The Digital Twin as a Service Enabler: From the Service Ecosystem to the Simulation Model | SpringerLink Manuscript for personal use.

The final authenticated version is available online at:

https://link.springer.com/chapter/10.1007/978-3-030-38724-2 25

https://doi.org/10.1007/978-3-030-38724-2_25

\title{
The Digital Twin as a Service Enabler: from the Service Ecosystem to the Simulation Model
}

\author{
Jürg Meierhofer ${ }^{1,3}$, Shaun West ${ }^{2,3}$, Mario Rapaccini ${ }^{4}$, Cosimo Barbieri ${ }^{4}$ \\ ${ }^{1}$ School of Engineering, ZHAW Zurich University of Applied Sciences, Switzerland \\ juerg.meierhofer@zhaw.ch \\ ${ }^{2}$ School of Engineering and Architecture, HSLU Lucerne University of Applied Sciences and \\ Arts, Switzerland \\ shaun.west@hslu.ch \\ ${ }^{3}$ Swiss Alliance for Data-Intensive Services, Expert Group Smart Services \\ ${ }^{4}$ School of Engineering, University of Florence \\ \{mario.rapaccini, cosimo.barbieri\}@unifi.it
}

\begin{abstract}
.
This paper investigates the concept of the digital twin as an enabler for smart services in the context of the servitization of manufacturing. In particular, a concept is developed and proposed for the derivation of appropriate simulation models starting from the model of the service ecosystem. To do so, smart industrial services are analyzed from the point of view of their value proposition. Next, the role of the digital twin as an enabler for these services is analyzed and structured in a multi-layer architecture. Hybrid simulation approaches are identified as suitable for building simulation models for this architecture. Finally, a procedural end-to-end approach for developing a simulation based digital twin departing from the service ecosystem is proposed.
\end{abstract}

Keywords: Smart Services, Servitization of Manufacturing, Digital Twin.

\section{Introduction}

The goal of this paper is to elaborate a concept for creating service value using a digital twin. The aim is to design and engineer services derived from the customer needs that leverage the potential of the digital twin. The approach discussed in this paper starts with the concept of "Service-Dominant Logic" (SDL). With the transition from products to services, the economy moves from the concept of "Goods-Dominant Logic" (GDL) to SDL. In SDL, service is considered the fundamental purpose of economic exchange (foundational premise 1, FP 1). The focus of value creation is moved from the manufacturer as creator to co-creation through customer interaction [1]. Here the quality of the service is determined by the customer's perception, rather than by the 
engineering on the side of the provider: hence, the value is always co-created by the customer (FP 6). Value is deployed over a period of time which exceeds the discrete moment of sales and distribution and is created in ecosystems through actor-generated institutions and institutional arrangements (FP 11).

SDL also states that operant resources - knowledge and skills - are the fundamental source of competitive advantage for the actors in the ecosystem (FP 4). Service providers apply their knowledge and skills for the benefit of another entity or the entity itself [1]. In the context of industrial services, the ability to use a digital twin based on databased models and analytics represents an operant resource. The concepts of SDL are translated into practical procedures by, e.g., service design approaches. According to [2], service design [3] can be considered an operationalization of SDL. When designing a new service, it is essential to first define and understand the target customers and to explore their needs for service in the specific context. The benefit for the customer depends strongly on the customer himself and on his individual situation and context (FP 10).

\section{Smart Industrial Services}

The service sector is continuously growing and makes up a substantial part of employment and the gross domestic product [4]. On the transition from products to services, companies start to move from the concept of GDL to SDL, and the concept of industrial companies as service providers has emerged [5]. The focus of firms' value creation, thus, shifts from the manufacturer to co-creation by firm and customer [1]. 

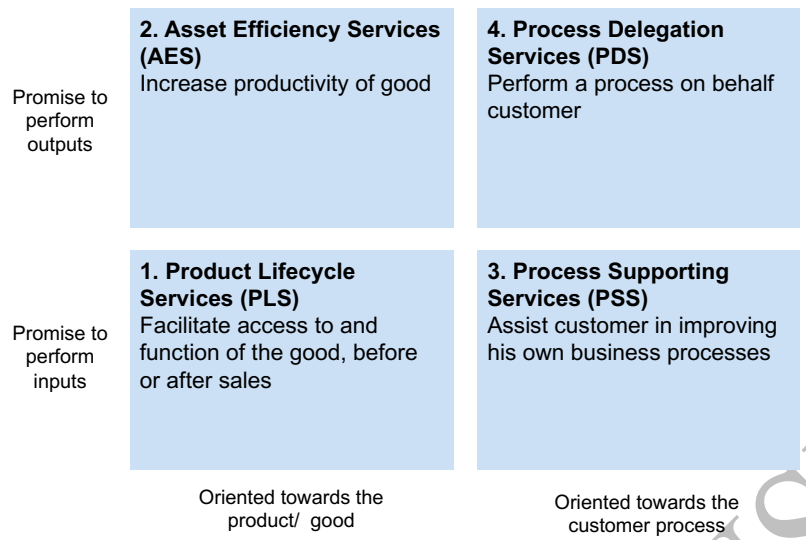

3. Process Supporting Services (PSS)

Assist customer in improving

his own business processes

Fig. 1. Input- vs. output-based services (adapted from [7])

The shift to services is driven by saturated markets and high competitive intensity [6], as well as by customer demand for the values and benefits provided by services [7]. In particular, there is an evolution for customers to demand and pay for some agreed performance output instead of the resource inputs the provider offers. Therefore, the transition from goods to services and the addition of services to products is considered essential for manufacturing firms [8]. For the development of this service economy, the omnipresence of information and communications technology is a major driving force [9].

The literature provides a classification of industrial services based on the value provided to the customer, who is guaranteed either an input or some output performance $[7,10])$. There is a differentiation between services that are oriented towards the supplier's goods or towards the customer's processes (Fig. 1). According to the figure, traditional service models are located in the PLS (product life-cycle services) quadrant. Examples are the installation of new equipment, maintenance, repair or spare parts delivery. When the provider moves to new service models around its products, the PLS services are complemented or replaced by output-oriented asset efficiency services (AES), such as customization, condition monitoring, predictive maintenance, performance optimization, or consulting for the customer along the end-to-end journey. New 
service models that focus on output performance are also referred to as "advanced services" [8]. This is in line with the concept of moving from value in exchange to value in use with the good becoming a distribution mechanism for the service value (FP 3). Assessing and quantifying the fluctuations and risks inherent to the output provided as well as the production costs to achieve the promised level of output quality, therefore, becomes a key capability for a provider when moving to output-based advanced services.

The provider needs to understand and manage the risk of failing to provide the guaranteed performance. It is evident that the ability to manage, process, and analyze data of the installed base is essential to do this. Therefore, with the increasing degree of servitization of manufacturing and in order to move to advanced services, leveraging data for the development and the provision of services becomes a key prerequisite, and at the same time it is a key challenge for the providers. In this perspective, the ability to process and analyze data is considered an operant resource according to SDL. The intention to move from basic services in the area of product life-cycle services to advanced asset efficiency services was confirmed in case studies with several manufacturing companies $[11,12]$.

\section{The Digital Twin as an Implementation Form of Smart}

\section{Services}

\subsection{Actors' Jobs and Needs over the Product Lifecycle}

Each actor within a firm's business ecosystem will have different jobs, pains, and gains and these are dependent on the situation in question; in effect, the actor's problem. The digital twin needs to match closely with "the actor's problem" in a systematic approach, so the resulting services are centered around the specific needs of the actor in that particular situation. This fosters a close relationship and co-creation of value between the different actors (e.g., the providers and the customers), which contributes to long-term relationships and loyalty. There is no single applicable value proposition but rather, many value propositions that are based around individual actors and their situational 
problems. In particular, the digital twin lends itself to contribute to the value propositions by supporting all of the actors around the product service system, in particular by relieving the pains and increasing the gains of the actors. As discussed before, the digital twin is based on a combination of data, analytics, and the visualization of the insights to support decision-making by providing advice. Depending on the phase of the product lifecycle (beginning, middle, end of life, i.e., BOL, MOL, EOL), different components of the twin and different data are required.

When designing and applying the digital twin, the provider applies its knowledge and skills in analyzing the needs of the different actors in the ecosystem and conceiving appropriate service value propositions based on data, modelling the physical equipment and combining this with domain specific knowledge to provide a service benefit. Therefore, the approach discussed in this paper considers the digital twin as a data-driven operant resource for the design and provision of services. The twin is structured according to technical and business hierarchies. The product, which is the carrier of the industrial service, on the one hand consists of sub-components and on the other hand is part of a larger system. Therefore, the objects considered in these layers may range from physical components and integrated machines, up to shop floors, factories, and systems of factories [13].

The research question in this study requires framing within the context of data-driven product service systems so that the complexities of the B2B (business to business) environment and digital twins can be investigated in the industrial world. Around this framing the research question is: "In a complex data-driven product service system, what service value can the digital twin provide, who is the provider, who is the beneficiary, and how can this service value be implemented by data and simulation models?"

\subsection{Layered Approach for Service Value Creation using the Digital Twin}

In this section, we discuss a structure of the digital twin that lends itself to the design of industrial services along the product lifecycle. From the perspective of the product life-cycle management phases (BOL, MOL and EOL), systematic service design delivers customer value in all these phases (Fig. 2). The actors in the ecosystem, i.e., the diverse actors along the product lifecycle, require value propositions that fit their jobs, 
pains, and gains. These diverse instances of value propositions are generated by the family of digital twins, consisting of several sub-twins each serving a specific sub-set of jobs, pains, and gains, and using specific elements of data and models.

According to [14], value creation based on data and analytics is very similar to that based on the digital twin. Data and analytics can be considered as an enabling part of the digital twin. Although technical discussions of the digital twin predominate in literature, there are also sources that illuminate the object from the perspective of services and value contribution. According to [15], the integration of the digital twin and service represents a promising research direction which should be addressed in future paradigms. [16] as well as [17] and [15] discuss the application of the digital twin along the product lifecycle. It can provide value in the form of services in product design and engineering, in the design and optimization of the shop floor, in product operations and usage monitoring, and in after-sales services and prognostics and health monitoring of the product. [18] discusses the digital twin as a basis of a decision support system in manufacturing.

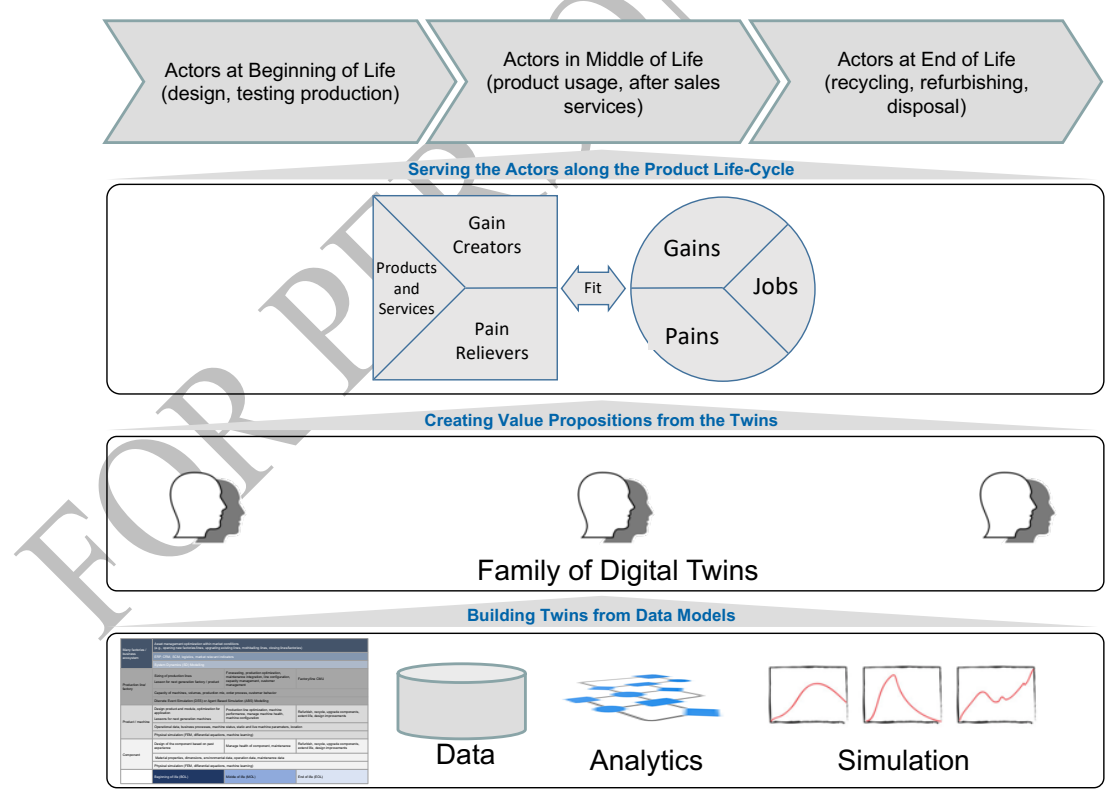

Fig. 2. Data enabled value creation framework of the simulation-based digital twin 
Given the wide range of interpretations of the term "digital twin", it becomes evident that further dimensions are required to get a differentiated perspective on the value contribution. A hypothesis for a layered approach adapted from [19] is shown in Fig. 3.

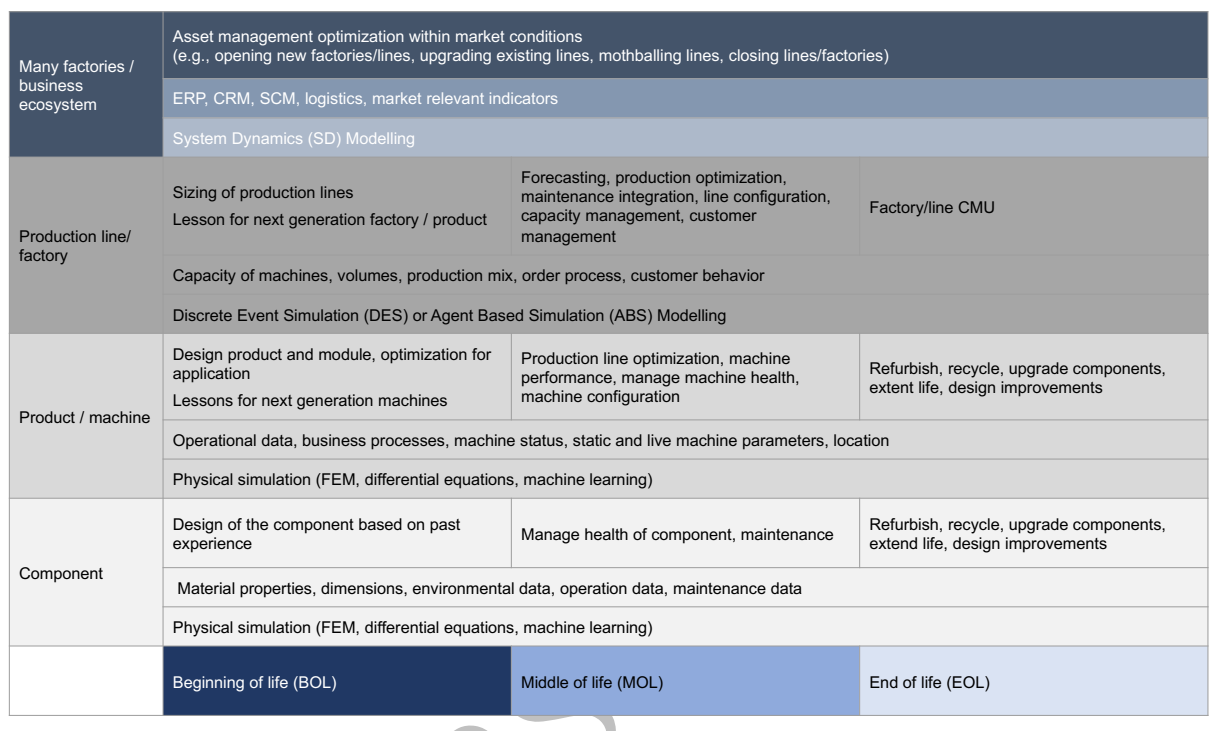

Fig. 3. Architecture of the digital twin in several layers with design objective, data used, and simulation technique applied

In this respect, the digital twin can be considered a data-driven enabler and support for providing services. The structuring of the twin along the phases of the product lifecycle as well as in the hierarchy of the technology and the business decisions leads to the concept of the family of twins. In each of the phases BOL, MOL, and EOL, a digital twin can provide service value to specific actors in the product service system. 


\section{Simulation Approaches for the Digital Twin}

\subsection{Literature Review for Simulation Approaches for Multi-Layer Manufacturing Systems}

Implementing a family of digital twins for the architecture shown in Fig. 3 requires the development of different elements of simulation models on a different level of granularity, which are then combined. The family of twins in a specific case may comprise elements covering different phases of BOL, MOL, or EOL, as well as different layers of the architecture, e.g., a machine layer as well as a factory layer.

Simulation across several layers in manufacturing environments is referred to as "hybrid simulation" in the literature [21, 22, 23, 24, 25]. "Hybrid simulation" is also methodologically further elaborated in $[26,27,28]$. Under this term, the three modelling approaches "agent-based simulation" (ABS), "discrete event simulation" (DES), and "system dynamics" (SD) are considered in a systematic and combined approach. According to [21], simulation in manufacturing systems today mainly focuses on DES, while the potential of ABS and SD are rather under-utilized. In [23], a comprehensive overview of eight issues in production planning and control is provided, together with an indication which of the simulation modelling approaches of ABS, DES, or SD is suited to each. These eight issues are: facility resource planning, capacity planning, job planning, process planning, shop floor scheduling, inventory management, production and process design, purchase and supply management. In [25] a hybrid approach of ABS and DES is elaborated for the modelling of a product-service-system and compared to an approach based only on DES. The study reveals that the hybrid approach is more useful for modelling the customer interaction in a service system. [24] elaborates on the specific challenges imposed by the high variability inherent in services systems. This is due to the co-creative involvement of a variety of customers as well as the provider resources in the process, which may be a cause of the "service paradox", i.e., companies suffering from poor return on their service business. Both [24] and [29] argue that simulation approaches are a suitable means to cope with these challenges of increased variability. They compare different hybrid approaches of ABS, DES, and SD, and conclude that the combination of ABS and DES is well suited for the modelling of 
manufacturing issues, where ABS makes modelling of customer variability easier and also allows the detection of phenomena as they emerge in the system. SD lends itself to, e.g., modelling sustainable cause-effects loops.

\subsection{Hybrid Simulation Concept for the Family of Digital Twins}

Given the simulation concepts available in the literature, it becomes obvious that a hybrid simulation approach comprising SD, DES, and ABS is adequate to support decision-making by the family of digital twins in industrial environments. Thus, the simulation models represent an operant resource that is integrated by the actors for providing a benefit for decision support.

\section{System Dynamics (SD) Modeling:}

- SD modeling is focused on the observation on the system level and used for strategic-level modeling. SD modeling uses the laws of physics to describe and investigate the dynamics of economic and social systems, whereby individual entities are not specifically modelled, but are represented as a continuous quantity in a stock. The mechanisms behind DS modeling are feedback loops and stock and flow models (e.g., for stocks of products or jobs or for flows of purchases).

- The target objects of the models in manufacturing systems are, for example: demand forecasting (on an aggregated level), estimation of total cost and revenues, network and supply chain planning, logistics and inventory planning, ecology modeling, supply, corporate planning, etc. [21, 23].

\section{Discrete Event Simulation (DES) Modeling:}

- DES modeling is used for process-oriented modelling of the behaviour and impact of actors or items in their ecosystem on an operational-tactical level. DES models can be considered as an interacting set of entities that evolve through different states while internal or external events happen. The system is frequently modeled as a process, i.e., a sequence of operations performed across entities and resources. 
- Discrete event simulation is the most common simulation methodology used for manufacturing systems. Target objects of the models are, for example, capacity planning, quantity planning, job-shop management, shop floor scheduling, order time planning etc. [21, 23].

\section{Agent-Based Simulation (ABS) Modeling:}

- ABS is a bottom up approach. The modelers do not need to know the complex structure and operation of the overarching system. Modeling starts with designing individual agents, defining their characteristics and behaviors. In the execution of the simulation models, they interact together their environment. Thus, agents in ABS are autonomous, heterogeneous and possibly intelligent entities. The evolution of the agents over time can be modeled by state charts inside agents. The global system behavior does not need to be defined. It emerges as a result of the evolution of the individual agents, each following its own rules [24].

- Agents may be, for instance, customers, machines, capacities, or goods flowing across a system. Therefore, in manufacturing contexts, ABS modeling is applied to job planning, equipment planning, process sequence planning, shop floor scheduling etc. or, e.g., cooperation and communication within the supply chain [21, 23].

\section{Physical Modeling:}

- In specific cases, the input data for feeding the digital twin may stem from physical sensors, e.g., vibrations, temperatures etc. This data can be used in a physical model that is combined with the other models, typically based on differential equations / FEM (e.g., [20]).

- However, in the context of decision support services in manufacturing environments, physical data can be used for models based on data science applications. The underlying methodologies are described in, e.g., [30], with the application for data-driven services discussed in [31]. 
- This can be used, for example, to assess or predict the status of machines by classification, based on physical input data. The discrete variables describing this status can then be fed into agents of ABS to factor into the decision-making process.

To conclude, as discussed in the literature about hybrid simulation models, the combined models of ABS and DES are most frequently applied in manufacturing systems. DES is used to model the work processes on the shop floor, in which raw-materials and semi-finished products are worked on by humans and machines. Throughput or waiting times based on queuing systems can be evaluated and used for the decision-making process supported by the digital twin. ABS can enhance the DES model by modulating the behavior of the actors (e.g., customers can change their needs based on contextual information, which is typical in service systems). Equally, human workers or machines can change their behavior over time. ABS can also be used for modeling autonomous material or products moving across the system.

In the architecture of the digital twin according to Fig. 3, SD simulation will be added at the top of the scheme if the behavior on the system level needs to be understood for decision support services. This may be, e.g., strategic evolutions at the supply chain level, or the impact of the production schemes on ecological variables. Additionally, where required, physical models can be supplemented at the bottom of the scheme in a targeted manner to integrate physical measurement points into the model.

\section{Integration of Sérvice Ecosystem and Simulation Model}

When hybrid simulation models according to section 4.2 and based on the architecture of Fig. 3 are implemented, it is important not to start building the entire system in a GDL approach, which would be followed by traditional simulation approaches (i.e., building a simulation model around a product or a physical system and then trying to get value out of this). According to [16], "The simulation models making-up the Digital Twin are specific for their intended use and apply the suitable fidelity for the problem to be solved.". [28] claims that the goal of a simulation modeling process is not to build a simulation model, but to build a decision support system. Taking the SDL perspective, the needs of the actors in the ecosystem and the value in use to be provided need to be 
modeled first. Only then, the application of simulation models to provide the value in use may be considered.

In the service design perspective, this means that first, the ecosystem of actors and their jobs, pains, and gains need to be modeled. Digital twins - in particular simulationbased ones - are only considered if they can add value to the service value proposition for supporting the actors in their decision processes. In practical cases, it often turns out that simulation-based digital twins are appropriate only for a specific subset of the customer jobs. Substantial components of the service are then based on other-not data or simulation based - components of knowledge and skill. This also means that the architecture of Fig. 3 is not implemented in its entirety, but specifically in individual elements to achieve the targeted service benefit. These elements then make up the members of the family of twins shown in Fig. 2.

Given this SDL perspective, we therefore elaborate and propose a procedure in six steps for the development of the digital twin starting from modelling the service ecosystem and leading to the integration of the technical resources (i.e., the simulationbased members of the family of twins).

\section{First, the ecosystem of actors in the system is analyzed and documented:}

- In agreement with the concept of SDL and in particular of service ecosystems, the boundaries of the system need to be determined by including those actors that are directly relevant for the use case and that may influence the decision to be taken.

- Service ecosystems are typically drawn in the form of a graph with the actors being the nodes and the connecting edges representing the transactions and the value flows [2].

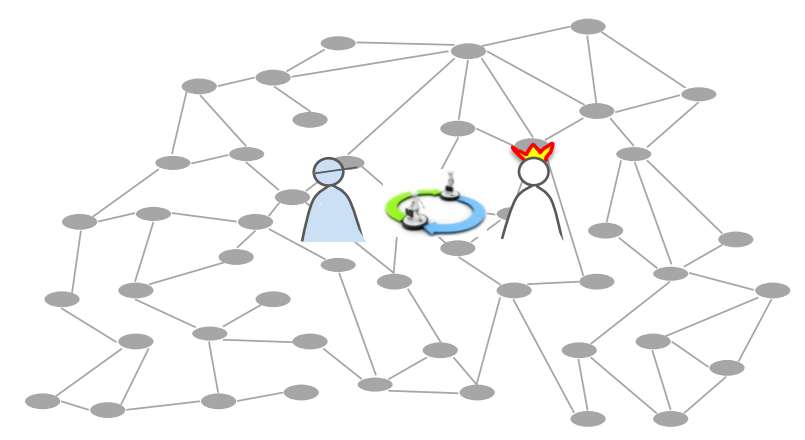


Fig. 4. Mapping the existing service ecosystem with different actors being interconnected by value exchanges that can be described by the transactions.

\section{Next, the problems of the actors are described using service design tools:}

- In particular, this means conducting contextual customer insight research and understanding the jobs to be done [3].

- This leads to documented actors' jobs, pains, and gains (see also Fig. 2), their customer journey, and their position in the service ecosystem.

\section{Next, the moments of truth for decision support are identified:}

- As discussed in section 4, hybrid simulation-based models (like physical modelling, SD, DES, or ABS) lend themselves to provide value in the form of decision support to the actors in the ecosystem. For deciding which simulation elements (i.e., members of the family of twins) provide most value, the most critical decision points of the actors are identified.

- In terms of the service design methodology, these are the moments of truth (MoT, [3]).

\section{For these identified decisions, their factors and impacts are analyzed:}

- What is driving the decision? Are there capacity constraints (e.g., not enough resources or agents)? Or are there capability constraints (e.g., not the right resources)? Are there other driving factors?

- Which information is required to assist the actor in the decision? How does it have to be presented to the actor in order to provide a service value?

- Which is the relevant time horizon for the service value? I.e., in which time horizon does the decision have an impact? E.g., an actor responsible for the maintenance of equipment may need to know how it will perform in the next days or weeks or months, depending on the context.

5. For the required information for decision support, the integrability of the technical resources is checked: 
- Which data and other technical resources (operant resources) are required to provide the required value to the actor?

- Are the resources available and can they be integrated? If not, can they be made available? Can they be simulated or emulated for estimating the potential of the new service?

\section{Build the models for the family members of the digital twin:}

- In order to provide the actor-specific service value, the technical models according to the concepts described in section 4 are built, thus making up the family of twins.

- These models then are integrated as resources in service value propositions, i.e., combined with other resources (that are typically not data- or simulation-based).

- Of course, according to the service design procedures (e.g., [3]), the development of the service value proposition follows an iterative approach, i.e., the service value is developed in a continuous cycle of "design - test - improve" steps until it provides the relevant value. This also means that the family of twins undergoes a continuous evolution.

If decision support for several actors in the system is developed, this means elaborating several family members of the twin, which together constitute the digital twin

\section{Discussion and Conclusions}

In this conceptual paper we derived a concept for modeling industrial service ecosystems based on the digital twin. We apply SDL to the digital twin concept, which means that the development process starts with understanding the business system and the problem of (all) the actors (e.g., people, things and processes) in the system. Transitions are identified between actors and then value propositions are derived from this and translated in appropriate members of the "family of twins". This results in a multi-layer approach for the required simulation models. The concepts around the topic "hybrid simulation" comprising ABS, DES, and SD described in the literature lend themselves to implementing parts of this architecture in simulation models. 
The application of "agency" is important as the simulation results should be viewed as advisory and limited by the system boundaries. There are many instances where the digital twin will have key management information missing. It should provide consequences of the advice and provide alternative options. In effect, we are suggesting that the data-driven models ("artificial intelligence", AI) do not hold all the answers but rather they are supportive to the decision making within the ecosystem. The AI here is made up of many digital twins and it is possible (or expected) that it may provide conflicting or unclear advice as it has used different underlying simulation models. A simple example of a digital twin providing advisory are the widely used navigation system apps and their travel services: options are provided both in terms of the mode of transport and routes - the digital twin here provides the consequences (e.g., travel times and complexity of journey). Finally, a digital helper then instructs the traveler.

The simulation based digital twin can be considered as a service agent when viewed through the lens of SDL. It should provide advice within the constraints of its boundaries as well as options allowing the human counterparties to take the action as the knowledge of the digital twin is limited to its bodies. It needs the use cases to be well understood and described and the sources of data and the beneficiaries of information to be defined. Based on this, we conclude that however the system is simulated, it should be brought all to the same level: people, machines and other objects as well as digital twins (including digital helpers) are all actors within the ecosystem.

In the ongoing and future research by the authors, a multiple case study is conducted to establish which of the modeling methodologies is most suitable to create value in which specific type of service situation. It is evaluated whether there are typical patterns and blueprints for selecting this methodology. Additionally, the amount and quality of the available data may limit the benefit of the services provided by the family of twins, which needs to be investigated. These investigations need to be conducted against the background of the business objectives of the actors in the ecosystem. Furthermore, it remains to be verified whether and how simulation agents in ABS lend themselves to the modelling of non-human actors in service ecosystems, which opens up new research questions in the area of the role of autonomous actors in service ecosystems [32]. 


\section{References}

1. Vargo, S., Maglio, P., Akaka, M.A.: On value and value co-creation: A service systems and service logic perspective, European Management Journal, Vol. 26, Issue 3, pp. 145-152 (2008).

2. Vargo, S.L., Lusch, R.F.: The SAGE handbook of service-dominant logic. SAGE, Los Angeles (2019).

3. Stickdorn, M., Hormess, M., Lawrence, A., Schneider, J.: This is Service Design Doing: Using Research and Customer Journey Maps to Create Successful Services, O'Reilly UK Ltd. (2017).

4. Kindström, D., Kowalkowski, C.: Service innovation in product-centric firms: a multidimensional business model perspective. Journal of Business \& Industrial Marketing, vol. 29, iss. 2, pp. $96-111$ (2014).

5. Lay G.: Introduction. In: Lay G. (eds): Servitization in Industry. Springer, Cham (2014).

6. Gebauer, H., Ren, G.-J., Valtakoski, A., Reynoso, J.: Service-driven manufacturing, provision, evolution and financial impact of services in industrial firms. Journal of Service Management, vol. 23, iss. 1, pp. $120-136$ (2012).

7. Kowalkowski, C., Ulaga, W.: Service strategy in action: a practical guide for growing your B2B service and solution business. Service Strategy Press (2017).

8. Baines, T., Lightfoot, H.W.: Servitization of the manufacturing firm, International Journal of Operations \& Production Management, vol. 34, iss. 1, pp. 2 - 35 (2013).

9. Chen, Y.G., Hsu, C.M., Chen, Z.H.: The Service Design Strategy of Manufacturing Service Industry. In: PICMET 2010 Technology Management for Global Economic Growth, pp. 1 $-6(2010)$.

10. Ulaga, W., Reinartz, W.J.: Hybrid Offerings: How Manufacturing Firms Combine Goods and Services Successfully. In: Journal of Marketing, vol. 75, no. 6, pp. 5-23 (2011).

11. Meierhofer, J.: Data driven servitization for SMEs in manufacturing. Spring Servitization Conference - Driving Competition through Servitization, pp. 101 - 108, Aston University, Birmingham (2018).

12. Meierhofer, J., Kugler, P., Etschmann, R.: Challenges and Approaches with Data-Driven Services for SMEs: Insights from a Field Study. In: Spring servitization conference: delivering services growth in the digital era, Lin-köping, Sweden, 13 - 15 May 2019. Birmingham: Aston University. pp. 39-49 (2019).

13. Porter, M.E., Heppelmann, J.E.: How Smart, Connected Products Are Transforming Competition. Harvard Business Review November, pp. 64 - 88 (2014). 
14. Qi, Q., Tao, F.: Digital Twin and Big Data Towards Smart Manufacturing and Industry 4.0: 360 Degree Comparison, in IEEE Access, vol. 6, pp. 3585 - 3593 (2018).

15. F. Tao and M. Zhang: Digital Twin Shop-Floor: A New Shop-Floor Paradigm Towards Smart Manufacturing. In IEEE Access, vol. 5, pp. 20418 - 20427 (2017).

16. Boschert S., Rosen R.: Digital Twin-The Simulation Aspect. In: Hehenberger P., Bradley D. (eds) Mechatronic Futures. Springer, Cham (2016).

17. Qi, Q., Tao, F., Zuo, Y., \& Zhao, D.: Digital Twin Service towards Smart Manufacturing. In Procedia CIRP, vol. 72, pp. 237 - 242 (2018).

18. Kunath, M., Winkler, H.: Integrating the Digital Twin of the manufacturing system into a decision support system for improving the order management process, procedia CIRP, vol. 72, pp. 225-231, (2018).

19. Meierhofer, J., West, S.: Service value creation using a digital twin. In: Naples Forum on Service, Service Dominant Logic, Network \& Systems Theory and Service Science: Integrating Three Perspectives for a New Service Agenda, Ischia, 4-7 June (2019).

20. Thiede, S., Schönemann, M., Kurle, D., Herrmann, C.: Multi-level simulation in manufacturing companies: The water-energy nexus case, Journal of Cleaner Production, vol. 139, pp. 1118 - 1127 (2016).

21. Scheidegger, A.P.G., Fernandes Pereira, T., Moura de Oliveira, M.L., Banerjee, A., Montevechi, J.A.B.: An introductory guide for hybrid simulation modelers on the primary simulation methods in industrial engineering identified through a systematic review of the literature, Computers \& Industrial Engineering, vol. 124, pp. 474 - 492, (2018).

22. Chandra C., Grabis J.: Simulation Modeling and Hybrid Approaches. In: Supply Chain Configuration. Springer, New York, NY (2016).

23. Min Jeon, S., Kim, G.: A survey of simulation modeling techniques in production planning and control (PPC), Production Planning \& Control, 27:5, pp. 360 - 377 (2016).

24. Rondini, A., Tornese, F., Gnoni, M.G., Pezzotta, G., Pinto, R.: Hybrid simulation modelling as a supporting tool for sustainable product service systems: a critical analysis, International Journal of Production Research, 55:23, 6932 - 6945, (2017).

25. Rondini A., Tornese F., Gnoni M.G., Pezzotta G., Pinto R.: Business Process Simulation for the Design of Sustainable Product Service Systems (PSS). In: Umeda S., Nakano M., Mizuyama H., Hibino H., Kiritsis D., von Cieminski G. (eds) Advances in Production Management Systems: Innovative Production Management Towards Sustainable Growth. APMS 2015. IFIP Advances in Information and Communication Technology, vol 460. Springer, Cham (2015). 
26. Eldabi, T., Balaban, M., Brailsford, S., Mustafee, N., E. Nance, R., Onggo, B.S., Sargent, R.G.: Hybrid Simulation: Historical lessons, present challenges and futures. Winter Simulation Conference (WSC), Washington, DC, 2016, pp. 1388 - 1403 (2016).

27. Brailsford, S.C., Eldabi, T., Kunc, M., Mustafee, N., Osorio, A.F.: Hybrid simulation modelling in operational research: A state-of-the-art review, European Journal of Operational Research, vol. 278, iss. 3, pp. $721-737$ (2019).

28. Lättilä, L., Hilletofth, P., Lin, B.: Hybrid simulation models - When, Why, How? Expert Systems with Applications, vol. 37, iss. 12, pp. 7969 - 7975, (2010).

29. Pezzotta, G., Rondini, A., Pirola, F., Pinto, R.: Evaluation of discrete event simulation software to design and assess service delivery processes. In: Tsan-Ming Choi, T.-S. (ed.): Service Supply Chain Systems, A Systems Engineering Approach. Kogan Page Ltd, London (2018).

30. Provost, F.P., Fawcett, T.: Data Science for Business. O'Reilly, Sebastopol, Calif. (2013).

31. Meierhofer J., Meier K.: From Data Science to Value Creation. In. Za S., Drăgoicea M., Cavallari M. (eds) Exploring Services Science. IESS 2017. Lecture Notes in Business Information Processing, vol 279. Springer, Cham (2017)

32. Maglio, P., Lim, Ch.: On the Impact of Autonomous Technologies on Humand-centered Service Systems. In: Vargo, S.L., Lusch, R.F.: The SAGE handbook of service-dominant logic. SAGE, Los Angeles, pp. 689 - 699 (2019). 